УДК 336.648 JEL G24

Дуненкова Елена

Николаевна

канд. экон. наук, доцент, ФГБОУ ВО

«Государственный университет

управления», г. Москва,

Российская Федерация

ORCID: 0000-0003-0414-6560

e-mail: en_dunenkova@guu.ru

\section{Лысова Елизавета}

\section{Александровна}

студент магистратуры, ФГБОУ ВО

«Государственный университет

управления», г. Москва,

Российкая Федерация

ORCID: 0000-0002-1727-5751

e-mail: elizaveta9721@gmail.com

\section{Elena N. Dunenkova}

Candidate of Economic Sciences, Associate Professor,

State University of Management, Moscow, Russia

ORCID: 0000-0003-0414-6560

e-mail: en_dunenkova@guu.ru

Elizaveta A. Lysova

Graduate Student, State University of Management, Moscow, Russia

ORCID: 0000-0002-1727-5751

e-mail:elizaveta9721@gmail.com

\section{ВЕНЧУРНЫЕ ЭКОСИСТЕМЫ РОССИИ И США: СРАВНИТЕЛЬНЫЙ АНАЛИЗ}

Аннотация. Целью исследования является анализ особенностей развития и текущего состояния основных элементов венчурных экосистем России и США. Для достижения указанной иели выявлены и проанализированы ключевые особенности изучаемых вечурных экосистем. Рассмотрена хронология этапов развития венчурных экосистем обеих стран, определено их текущее состояние, включающее объемы и количество заключенных венчурных сделок, их соотночение по стадиям инвестиционного процесса. Выделены ключевые различия сочиокультурных факторов и нормативно-правовых баз, регламентирующих и влияющих на деятельность венчурных экосистем. Выявлены основные проблемные моменты развития инновационного потенциала Российской Федерация и причины их возникновения. Проведен сравнительный анализ венчурной индустрии России и США, на его основании выявлены ключевые проблемы, препятствующие развитию венчурной экосистемы России, даны рекомендации по их преодолению.

Ключевые слова: венчурная экосистема, венчурные инвестиции, венчурный капитал, венчурный фонд, высокотехнологичные проекты, инвестиции, инновации, инновационная деятельность, инновационный потенцииал, инновационный процеесс, Россия, США

Для цитирования: Дуненкова Е.Н., Лысова Е.А. Венчурные экосистемы России и США: сравнительный анализ//Вестник университета. 2020. № 12. С. 95-102.

\section{VENTURE ECOSYSTEM IN RUSSIA AND THE UNITED STATES: A COMPARATIVE ANALYSIS}

Abstract. The aim of the research is to analyse the features of development and current state of the main elements of venture ecosystem in Russia and the United States. To achieve this goal, the authors reveal and analyse the key features of the studied natural ecosystems. The paper considers the chronology of the stages of development of venture ecosystems in both countries, determines their current state, including the volume and number of concluded venture transactions, their ratio by stages of the investment process. The article highlights the key differences between socio-cultural factors and legal frameworks that regulate and influence the activities of venture ecosystems. The study identifies the main problematic aspects of the development of the innovative potential of the Russian Federation and the reasons for their occurrence. The authors carry out a comparative analysis of the venture industry in Russia and the United States, identify on its basis, the key problems that hinder the development of the venture ecosystem in Russia, and give recommendations for overcoming.

Keywords: high-tech projects, innovations, innovative activity, innovative capacity, innovative process, investments, Russia, USA, venture capital, venture capital ecosystem, venture capital fund, venture capital investments

For citation: Dunenkova E.N., Lysova E.A. (2020) Venture ecosystem in Russia and the United States: a comparative analysis. Vestnik universiteta. I. 12, pp. 95-102. DOI: 10.26425/1816-4277-2020-12-95-102

В настоящее время, в условиях глобализации мировой экономики и ускорения научно-технического прогресса, основными факторами роста конкурентоспособности национальной экономики является стимулирование инновационной деятельности и развитие научно-производственного потенциала. В России этим факторам уделяют особое внимание в рамках реализации стратегических инициатив по переходу от традиционной сырьевой к инновационной экономике. В мировой практике основным источником финансирования инноваций, обеспечивающим приток капитала в развитие инновационной деятельности, являются венчурные инвестиции.

Актуальность настоящей работы обусловлена необходимостью проведения детализированного анализа факторов развития венчурной экосистемы в России и США для формулирования выводов и разработки рекомендаций по улучшению отдельных ее элементов в нашей стране. Для этого необходимо провести сравнение основных элементов венчурной экосистемы обеих стран, на основе которого будут выявлены текущие проблемы венчурной индустрии России, и предложить решения для их корректировки на основе американского опыта.

( Суненкова Е.Н., Лысова Е.А., 2020. Статья доступна по лицензии Creative Commons «Attribution» («Атрибуция») 4.0. всемирная (http://creativecommons.org/licenses/by/4.0/).

The Author(s), 2020. This is an open access article under the CC BY 4.0 license (http://creativecommons.org/licenses/by/4.0/).

(c) (i) 
В ходе исследования применены следующие методы:

- изучение открытых источников информации: научных, деловых и новостных;

- анализ статистических данных с целью получения количественной и качественной оценки мирового опыта формирования венчурной индустрии;

- синтез данных из различных источников, обобщение информации для формирования единого понимания мирового опыта в вопросе влияния институциональной и социокультурной сред на состояние и уровень развития венчурной экосистемы;

- сравнение подходов к формированию отдельных элементов венчурной экосистемы для определения ключевых различий между венчурной индустрией США и Российской Федерацией (далее - РФ);

- моделирование возможных особенностей внедрения практики в России.

Рассмотрим венчурную экосистему США, историю ее развития, текущее состояние, ключевые особенности.

Становление американской венчурной экосистемы происходило с конца 40-х гг. до конца 70-х гг. $\mathrm{XX}$ в. Ее началом послужило основание первого венчурного фонда - American Research and Development (ARD), основанного в Бостоне в 1946 г., после окончания Второй мировой войны. Деятельность фонда была преимущественно направлена на приобретение малых высокорисковых компаний, выстраивающих свою деятельность, применяя и адаптируя технологии военного предназначения для потребностей активно развивавшегося в тот период промышленного производства [4]. К середине 1950-х гг. венчурный капитал окончательно закрепился в статусе альтернативного источника финансирования бизнеса. Именно в этот период при помощи привлечения венчурных инвестиций был дан старт многим высокотехнологичным транснациональным компаниям, например, Intel. Однако, несмотря на то, что в указанный период правительство и предприниматели приняли активные шаги по выстраиванию гармоничной венчурной экосистемы (к примеру, была создана Национальная ассоциация венчурного капитала (NVCA) с целью формирования положительного общественного мнения и защиты интересов венчурных капиталистов), малое количество заинтересованных инвесторов и, как следствие, дефицит денежных средств обусловили медленное развитие рынка.

Настоящее развитие венчурная экосистема получила в начале 1970-х гг., и данный процесс, сопровождался институциональными изменениями, направленными как на прямую, так и косвенную поддержку венчурной экосистемы, обусловил ее становление как самой активной системы в мире.

Одним из самых главных институциональных изменений можно считать принятие закона о безопасности пенсионных отчислений, который позволил пенсионным фондам США оперировать частью капитала для инвестиций в венчурную деятельность [8]. Позже аналогичный закон был принят в отношении страховых компаний, благотворительных и некоммерческих фондов. Принятие данных законов позволило привлечь в венчурную индустрию США крупные объемы капитала, что, в свою очередь, отразилось на инвестиционной активности. На данный момент именно пенсионные фонды и страховые компании являются основными держателями венчурного капитала. Другим важным институциональным изменением стало принятие Акта об увеличении акционерного капитала малого бизнеса [4]. Благодаря этому акту инвестиционные компании могли получить отсрочку по выплатам облигационных займов до момента достижения указанного уровня доходности, что обусловило возросшее количество игроков на венчурном рынке.

Среди косвенных элементов поддержки венчурной индустрии США можно выделить три основных направления.

1. Принятие законодательных актов, основной целью которых являлось повышение коммерческой значимости уже ранее финансировавшихся исследований, которые проводились и проводятся в университетах и государственных исследовательских центрах. Среди примеров подобных инициатив можно выделить закон Бэя-Доула, принятый в 1980 г., главная цель которого - стимулировать ученых выходить со своими открытиями на рынок, создавать свои компании или продавать лицензии на технологии другим фирмам.

2. Содействие финансированию научно-исследовательских и опытно-конструкторских разработок (НИОКР), производящихся отдельными компаниями, для чего в 1980-х гг. был принят ряд федеральных программ. Финансирование инноваций в США осуществляется исходя из следующих пропорций: 35 \% инвестиций - из федерального бюджета; 60 \% инвестиций - из собственных средств производственных компаний; 5 \% инвестиций - из средств правительств штатов, органов местного самоуправления [5]. 
3. Программы и законодательные акты (к примеру, снижение ставки налога на прибыль), основной целью которых является финансирование и поддержка малых инновационных предприятий. К подобным программам относят:

- Программу поддержки инновационных исследований малого бизнеса» (The Small Business Innovation Research Program - SBIR);

- Программу по распространению технологий малого бизнеса» (The Small Business Technology Transfer Program - STTR);

- Программу по созданию инвестиционных компаний для малого бизнеса» (The Small Business Investment Company - SBIC).

Указанные программы координируются Администрацией малого бизнеса США и частично финансируются из федерального бюджета [7]. Основной целью программ SBIR и STTR является развитие стратегически важных направлений инновационной деятельности на государственном уровне. Программа SBIR с суммарным годовым бюджетом более 1 млрд долл. США каждый год позволяет реализовать более 950 инновационных проектов. По программе SBIC государство финансирует деятельность молодых компаний, если предприниматель смог привлечь средства частных инвесторов в соотношении 2:1 или 3:1 [7].

Другим немаловажным фактором, обусловливающим высокую активность американской венчурной индустрии, является развитость фондовых рынков. Например, биржа NASDAQ (вторая после Нью-Йоркской), предназначена для торговли акциями преимущественно высокотехнологичных компаний. По состоянию на 2020 г., на бирже представлено 2649 подобных организаций со всего мира [13].

Основными социокультурными факторами, оказывающими влияние на развитие венчурной экосистемы США, являются, прежде всего, кадровый потенциал, а также высокий уровень финансовой грамотности населения. Вследствие использования специальных центров по подготовке и консультированию специалистов венчурной индустрии (к примеру, Annual Venture Capital Institute), а также высокого уровня образования населения, США обладает большим кадровым потенциалом в области венчурной индустрии. Высокий уровень финансовой грамотности населения также оказывает положительное влияние на венчурный рынок, так как это означает, что как предприниматели, так и остальные граждане страны умеют эффективно применять финансовые инструменты, в том числе и на венчурном рынке. Объем и количество инвестиций в период 2009-2019 гг., осуществленных венчурными фондами США, представлены в Отчете о состоянии венчурной индустрии США в 2019 г. [12, с. 5].

В период 2018-2019 гг. количество сделок с участием американского венчурного капитала показывало активный рост (10,777 сделок в 2019 г. и 10,542 сделки в 2018 г.). Несмотря на то, что объем сделок в 2019 г. снизился по сравнению с 2018 г. (136,6 млрд долл. США и 140,2 млрд долл. США соответственно), в 2019 г. было зарегистрировано 237 мега-сделок, что является значительным увеличением по сравнению с 2018 г. (211 сделок). Нетрадиционные венчурные инвесторы, такие как корпорации, хедж-фонды, инвестиционные банки и т. д., участвовали в более чем 85,0 \% подобных сделок [12]. Распределение венчурных инвестиций по стадиям жизненных циклов, финансируемых стартапов в период 2014-2019 гг. представлено в Отчете о состоянии венчурной индустрии США в 2019 г. [12, с. 5].

Из анализа приведенных выше данных следует, что основное количество инвестиций направлено на ранние стадии развития стартапов (4 556 на посевной стадии, 3600 на ранней и 2500 на поздней), однако основной объем инвестиций приходится на позднюю стадию - 85 млрд долл. США, тогда как общий объем инвестиций на начальных стадиях составил 51,1 млрд долл. США [12].

Далее, рассмотрим венчурную экосистему России.

Официально зарождение венчурной индустрии РФ датируется 1993 г. Причиной этого события стал саммит Большой Четверки в Токио, на котором были заключены договоренности о создании первых в России региональных фондов поддержки малого и среднего предпринимательства. Основной целью данных фондов стало оказание поддержки компаниям, работающим прежде всего в секторе товаров народного потребления.

Однако фактически венчурная индустрия возникла в 1997 г., что связано с появлением Российской ассоциации венчурного инвестирования (РАВИ), состоящей из двенадцати венчурных фондов, функционирующих на территории РФ [6]. Основной целью ассоциации было заявлено поддержание благоприятного инвестиционного климата. В том же году были созданы первые венчурные фонды, связанные с крупными российскими банками и предприятиями. 
В начале 2000-х гг. понятие венчурного финансирования стало использоваться на государственном уровне. В «Основных направлениях развития внебюджетного финансирования высокорисковых проектов в научно-технической сфере на 2000-2005 годы» были впервые даны определения венчурного инвестирования, венчурного предприятия, системы венчурного инвестирования [2].

Дальнейшее развитие венчурной индустрии РФ тесно связано с государством и институтами инновационного развития, такими как ОАО «РВК», ОАО «РОСНАНО», фонд «Сколково» и др. Активная деятельность данных организаций была направлена на разработку и вывод на рынок разнообразных финансовых и нефинансовых инструментов поддержки и развития высокотехнологичного предпринимательства, привлечение иностранных инвесторов на венчурный рынок РФ и формирования интереса к технологическому предпринимательству в целом [6]. Все это послужило мощным толчком для развития российской венчурной экосистемы.

В настоящее время институты развития и государственные инициативы продолжают оказывать положительное влияние на развитие национального венчурного рынка посредством реализации следующих программ.

1. «Цифровая экономика Российской Федерации» [1].

2. Проект Министерства экономического развития РФ «Национальные чемпионы» [11].

3. Межведомственная программа «Национальная технологическая инициатива» и т. д. [10].

Также значимую роль играет «Стратегия развития рынка прямых и венчурных инвестиций в Российской Федерации на период до 2025 года и дальнейшую перспективу до 2030 года», разработанная РВК [3]. Стратегия предполагает реализацию последовательных шагов, направленных на активизацию венчурной индустрии РФ: модернизация инфраструктуры поддержки высокотехнологичного предпринимательства; мероприятия, направленные на привлечение иностранного капитала в венчурную экосистему РФ; совершенствование нормативно-правовой базы и т. д.

Спад венчурной индустрии в 2014 г. можно считать начальной точкой текущего состояния венчурной индустрии РФ. Такая ситуация была обусловлена сложной макроэкономической ситуацией, возникшей в стране в тот период. Однако начиная с 2017 г. рынок начал постепенно стабилизироваться, приспособившись к непростой экономической и внешнеполитической ситуации и в 2018 г., показал лучшие результаты за последние 4 года [9].

По состоянию на 2018 г. в России функционировало 189 венчурных фондов, общий объем капитализации которых составил 4173 млн долл. США. Частные фонды составили около 77 \% от числа новых фондов в 2018 г. Общий объем венчурных инвестиций составил в 2018 г. 172 млн долл. США, что на 29 \% больше, чем в 2017 г. (133 млн долл. США), и является лучшим показателем с 2014 г. Причиной данного роста стало увеличение инвестиций в компании на стадии зрелости (рис. 1).

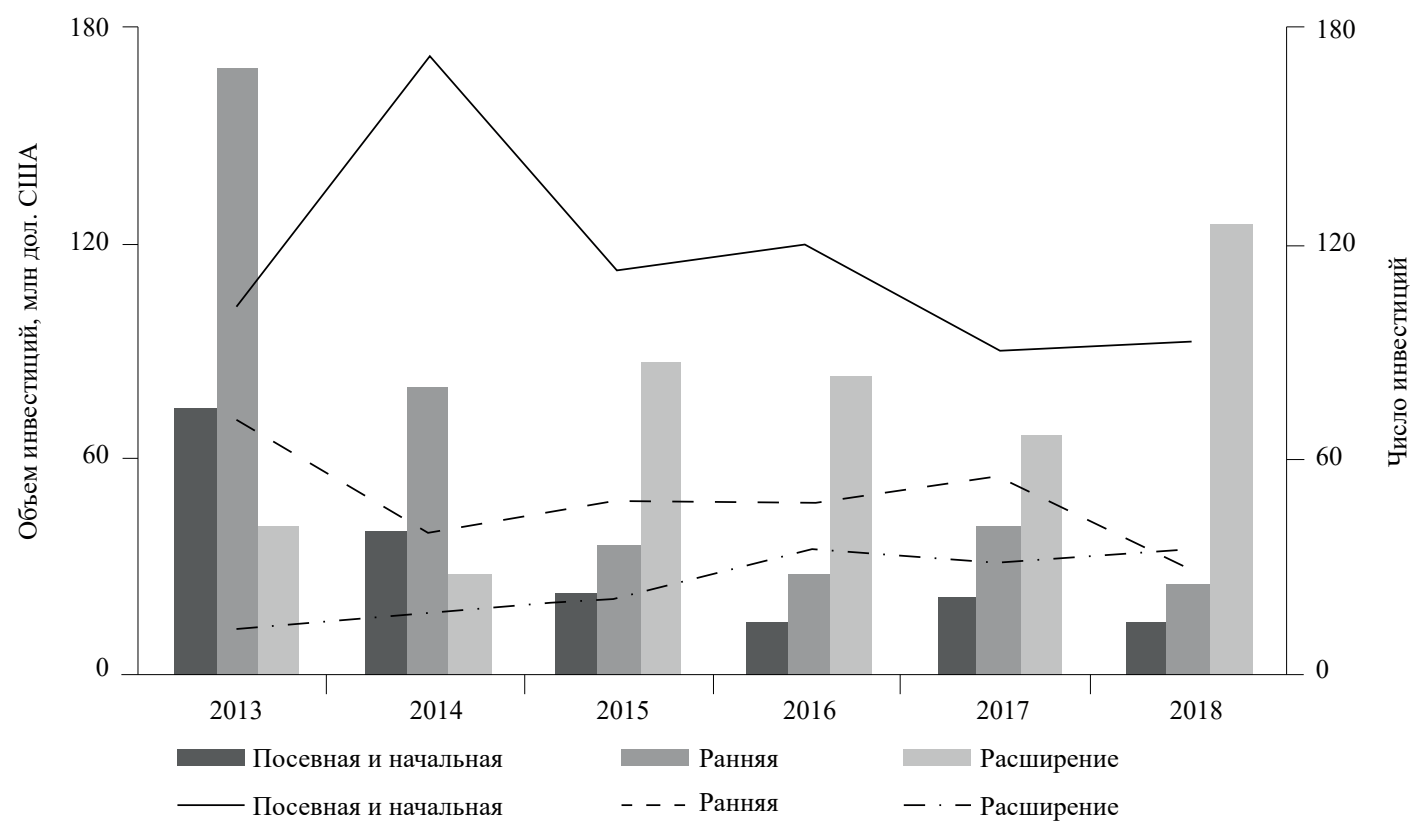

Составлено по материалам источника: [9]

Рис. 1. Распределение венчурных инвестиций по стадиям жизненного цикла стартапов 2013-2018 гг. 
Основной тенденцией 2018 г. стало увеличение объема инвестиций в компании зрелых стадий. С точки зрения количества осуществленных инвестиций 60 \% (94 шт.) пришлось на компании на посевной и начальной стадиях, $22 \%$ на стадию расширения и $18 \%$ на раннюю стадию соответственно. Таким образом, сопоставляя данную тенденцию с мировым опытом, можно сделать вывод, что в настоящий момент основные фокусы венчурных инвестиций в США и РФ полностью совпадают.

Однако, несмотря на положительные тенденции развития, венчурная индустрия РФ имеет множество проблем, которые препятствуют ее гармоничному развитию.

Одной из ключевых проблем развития венчурной экосистемы РФ сегодня является несовершенство нормативно-правовой базы. Нормативно-правовая база является ключевым фактором развития венчурной индустрии, так как именно она регламентирует наиболее важные вопросы для венчурных предпринимателей: авторские права, защиту интеллектуальной собственности и т. д. В российском законодательстве эти статьи до конца не проработаны, вследствие чего возникают сложности при регистрации инновации, закреплении прав на нее, внедрении на рынок и пр. По этой причине большое количество предпринимателей регистрируют компании за рубежом, а в России оформляют представительство. Налоговое законодательство также не адаптировано к потребностям венчурной индустрии: отсутствуют механизмы стимулирования малых высокотехнологичных компаний, а иностранные фонды вынуждены платить повышенные налоги. Также большой проблемой является то, что ключевые российские держатели капитала - пенсионные фонды и страховые компании - ведут свою деятельность в условиях нормативных ограничений, не позволяющим им осуществлять инвестиции на венчурном рынке. Этим обстоятельством объясняется дефицит денежных ресурсов в венчурной экосистеме.

Другой проблемой является небольшой объем фондового рынка РФ. Отсутствие механизмов и инструментов для размещения акций малых и средних высокотехнологичных предприятий на бирже, усложняет процесс «выхода» из инвестиционного процесса и снижает ликвидность инвестиций для венчурных инвесторов, а также сужает круг возможностей привлечения капитала для высокотехнологичных компаний.

В качестве других проблем, сдерживающих развитие венчурной экосистемы РФ, можно выделить следующие.

1. Дефицит высококвалифицированных кадров.

Данная проблема обусловлена несколькими факторами: тенденцией к активной утечке перспективных кадров за рубеж, отсутствием программ специальной подготовки специалистов для венчурной индустрии и т. д.

2. Низкий уровень предпринимательской активности и финансовой грамотности населения.

Согласно международным исследованиям, РФ характеризуется одним из самых низких уровней развития предпринимательской активности: доля работоспособного населения, желающего заняться предпринимательской деятельностью, составляет всего 2 \%, по данной позиции Россия находится на шестьдесят четвертом месте из шестидесяти четырех возможных [11]. Данная позиция обусловлена тем, что население низко оценивает собственную финансовую грамотность и предпринимательские компетенции. Доля населения, занимающегося предпринимательством, также невелика - 9,6 \% среди респондентов в возрасте 25-34 лет (47 место из 64), 6,3 \% населения в возрастной категории 35-40 лет (56 место) [3].

На основе приведенной выше информации можно составить сравнительную таблицу элементов венчурной экосистемы РФ и США (табл. 1).

Сравнительная таблица элементов венчурной экосистемы РФ и США

Таблица 1

\begin{tabular}{|l|c|c|}
\hline \multicolumn{1}{|c|}{ Показатель } & \multicolumn{2}{|c|}{ Государство } \\
\cline { 2 - 3 } & \multicolumn{1}{|c|}{ США } & РФ \\
\hline $\begin{array}{l}\text { Адаптированность нормативно-правовой базы } \\
\text { к потребностям венчурной индустрии }\end{array}$ & Высокая \\
\hline $\begin{array}{l}\text { Налоговая система, адаптированная к потребностям } \\
\text { венчурной индустий }\end{array}$ & Да & Нет \\
\hline
\end{tabular}


Окончание табл. 1

\begin{tabular}{|c|c|c|}
\hline \multirow{2}{*}{ Показатель } & \multicolumn{2}{|c|}{ Государство } \\
\hline & США & $\mathbf{P \Phi}$ \\
\hline $\begin{array}{l}\text { Наличие программ государственной поддержки } \\
\text { венчурной индустрии }\end{array}$ & Да & Да \\
\hline Преобладающий тип инвестора венчурного капитала & $\begin{array}{l}\text { Пенсионные и страховые } \\
\text { фонды, частные инвесторы, } \\
\text { корпорации }\end{array}$ & $\begin{array}{l}\text { Преобладающая роль государ- } \\
\text { ства, частные фонды }\end{array}$ \\
\hline Наличие развитых фондовых рынков & Да & Нет \\
\hline Наличие высокого уровня кадрового потенциала & Да & Нет \\
\hline Положительное влияние социокультурной среды & Да & Нет \\
\hline
\end{tabular}

Составлено авторами по материалам исследования

Из данных таблицы следует, что российская венчурная экосистема находится на стадии зарождения и значительно отстает от американской.

Сформулируем первостепенные задачи, решение которых будет способствовать совершенствованию и развитию российской венчурной экосистемы.

1. Адаптация налоговой, патентной и пр. законодательных баз под нужды и потребности венчурной индустрии, а также снятие законодательных ограничений на осуществление инвестиций негосударственными пенсионными фондами и страховыми компаниями, являющимися крупными держателями капитала.

2. Повышение финансовой грамотности и развитие предпринимательских компетенций населения. Этому вопросу необходимо уделить повышенное внимание, так как подобные улучшения носят стратегический характер и оказывают долгосрочное влияние на развитие венчурной экосистемы и инновационного предпринимательства в целом.

3. Развитие внутреннего фондового рынка РФ. Упрощение выхода из инвестиционного процесса, повышение ликвидности инвестиций окажут благотворное влияние на состояние венчурной индустрии РФ.

4. Повышение уровня кадрового потенциала. Необходимо наладить сотрудничество с передовыми зарубежными венчурными фондами для обмена опытом и повышения квалификации специалистов, создать центры, обеспечивающие обучение и поддержку венчурных предпринимателей.

Таким образом, в работе проведен анализ особенностей развития и текущего состояния основных элементов венчурных экосистем России и США, в ходе которого выявлено, что текущие рамочные нормативноправовые условия, сложившиеся в венчурной индустрии РФ, не соответствуют мировым стандартам в данной области и в сочетании с прочими проблемами сильно замедляют темпы развития отрасли. На основе мирового опыта становления венчурной экосистемы были обозначены направления преодоления главных проблемных моментов венчурного рынка РФ.

Преодоление перечисленных препятствий объективно необходимо для ускорения инновационного развития страны и имеет стратегическое значение для усиления конкурентоспособности национальной экономики.

\section{Библиографический список}

1. Программа «Цифровая экономика Российской Федерации» // СПС «КонсультантПлюс» [Электронный ресурс]. - Режим доступа: http://www.consultant.ru/document/cons_doc_LAW_308390/4b8af8bcbffd0a58fc980c11f6e5d2fb12304cf0/ (дата обращения: 15.11.2020).

2. Стратегия развития науки и инноваций в Российской Федерации на период до 2015 г. (утв. Межведомственной комиссией по научно-инновационной политике (протокол от 15.02.2006 № 1)) // СПС «КонсультантПлюс» [Электронный pecypc]. - Режим доступа: http://www.consultant.ru/document/cons_doc_LAW_101907/a677e7ba0f4d0b7696c62f326ca9 624e1 fa18add/ (дата обращения: 15.11.2020). 
3. Стратегия развития рынка венчурных и прямых инвестиций в Российской Федерации на период до 2025 г. и дальнейшую перспективу до 2030 г. [Электронный ресурс]. - Режим доступа: https://www.rvc.ru/upload/iblock/898/VC_Market_ Development_Strategy_2019.pdf (дата обращения: 15.11.2020).

4. Аммосов, Ю. П. Венчурный капитализм: от истоков до современности. - СПб.: РАВИ, 2004. - 409 с.

5. Баранов, А. О., Музыко, Е. И., Павлов, В. Н. Оценка эффективности инновационных проектов с использованием опционного и нечетко-множественного подходов. - Новосибирск: ИЭОПП СО РАН, 2018. - 336 с.

6. Овчинникова, Л. С. Формирование механизмов венчурного инвестирования в России // Россия и Америка в XXI веке.2016. - № 2 .

7. Рыхтик, М. И., Корсунская, Е. В. Национальная инновационная система США: история формирования, политическая практика, стратегии развития // Вестник Нижегородского университета им. Н. И. Лобачевского. - 2012. - № 6 (1). - С. $263-268$.

8. Филиппов, А. Г., Груздева, Е. В. Модели венчурных инвестиций в России и США как основной элемент становления инновационных предприятий // МИР (Модернизация. Инновации. Развитие). - 2019. - № 4. - С. 501-515 с.

9. Обзор рынка прямых и венчурных инвестиций за 2018 год (РАВИ) [Электронный ресурс]. - Режим доступа: http://www. rvca.ru/upload/files/lib/RVCA-yearbook-2018-Russian-PE-and-VC-market-review-ru.pdf (дата обращения: 15.11.2020).

10. Официальный сайт межведомственной программы «Национальная технологическая инициатива» [Электронный ресурс].- Режим доступа: https://nti2035.ru/nti/ (дата обращения: 15.11.2020).

11. Официальный сайт проекта «Национальные чемпионы» [Электронный ресурс]. - Режим доступа: http://nationalchampions.ru/ (дата обращения: 15.11.2020).

12. Отчет о состоянии венчурной индустрии США в 2019 г. / NVCA [Электронный ресурс]. - Режим доступа: https://nvca. org/wp-content/uploads/2020/01/Q4_2019_PitchBook_NVCA_Venture_Monitor.pdf (дата обращения: 15.11.2020).

13. Официальный сайт NASDAQ [Электронный ресурс]. - Режим доступа: https://www.nasdaq.com/market-activity/stocks (дата обращения: 15.11.2020).

\section{References}

1. Programma “Tsifrovaya ekonomika Rossiiskoi Federatsii” [Program "Digital Economy of the Russian Federation”]. Legal reference system "ConsultantPlus". Available at: http://static.government.ru/media/files/9gFM4FHj4PsB79I5v7yLVuPgu4bvR7M0.pdf (accessed 15.11.2020).

2. Strategiya razvitiya nauki i innovtsii v Rossiiskoi Federatsii na period do 2015 goda (utv. Mezhvedomstvennoi komissiei po nauchno-innovatsionnoi politike (protocol ot 15.02.2006 № 1)) [Strategy for the Development of Science and Innovation in the Russian Federation for the Period up to 2015 (Approved by the Interdepartmental Commission on Science and Innovation policy (Protocol No. 1 dated on February 15, 2006))]. Legal reference system "ConsultantPlus". Available at: http:/(www.consultant.ru/document/ cons_doc_LAW_101907/a677e7ba0f4d0b7696c62f326ca9624e1fa18add/(accessed 15.11.2020).

3. Strategiya razvitiya rynka venchurnykh i pryamykh investitsii v Rossiiskoi Federatsii na period do 2025 goda i dal'neishuyu perspektivu do 2030 goda [Strategy for the development of the venture and direct investment market in the Russian Federation for the period up to 2025 and beyond until 2030]. Available at: https://www.rvc.ru/upload/iblock/898/VC_Market_Development_Strategy_2019.pdf(accessed 15.11.2020).

4. Ammosov Yu. P. Venchurnyi kapitalizm: ot istokov do sovremennosti [Venture capitalism: from its origins to the present]. St. Petersburg, RAVI, 2004, 409 p.

5. Baranov A. O., Muzyko E. I., Pavlov V. N. Otsenka effektivnosti innovatsionnykh proektov s ispol'zovaniem optsionnogo i nechetko-mnozhestvennogo podkhodov [Evaluating the effectiveness of innovative projects using optional and fuzzy multiple approaches]. Novosibirsk, IEOPP SO RAN, 2018, 336 p.

6. Ovchinnikova L. S. Formirovanie mekhanizmov venchurnogo investirovaniya v Rossii [Formation of venture investment mechanisms in Russia]. Rossiya i Amerika v XXI veke [Russia and America in the XXI century], 2016, no. 2.

7. Rykhtik M. I., Korsunskaya E. V. Natsional'naya innovatsionnaya sistema SShA: istoriya formirovaniya, politicheskaya praktika, strategii razvitiya [National innovation system of the USA: history of formation, political practice, development strategies]. Vestnik Nizhegorodskogo universiteta im. N. I. Lobachevskogo [Vestnik of Lobachevsky University of Nizhni Novgorod]. 2012, no. 6 (1), pp. 263-268.

8. Filippov A. G., Gruzdeva E. V. Modeli venchurnykh investitsii v Rossii i SShA kak osnovnoi element stanovleniya innovatsionnykh predpriyatii [Models of venture investment in Russia and the United States as the main element of the formation of innovative enterprises]. MIR (Modernizatsiya.Innovatsii.Razvitie) [MIR (Modernization. Innovation. Research)], 2019, no. 4, pp. 501-515. 
9. Obzor rynka pryamykh i venchurnykh investitsii za 2018 god (RAVI) [Overview of the private equity and venture capital investment market for 2018 (RAVI)]. Available at: http://www.rvca.ru/upload/files/lib/RVCA-yearbook-2018-Russian-PE-andVC-market-review-ru.pdf (accessed 15.11.2020).

10. Ofitsial'nyi sait mezhvedomstvennoi programmy "Natsional'naya tekhnologicheskaya initsiativa" [Official website of the interdepartmental program "National Technology Initiative”]. Available at: https://nti2035.ru/nti/ (accessed 16.08.2020).

11. Ofitsial'nyi sait proekta "Natsional'nye Chempiony" [Official website of the project "National Champions"]. Available at: http://national-champions.ru/ (accessed 15.11.2020).

12. Otchet o sostoyanii venchurnoi industrii v SShA v 2019 g. [Report on the State of the US Venture Capital Industry in 2019]. NVCA. Available at: https://nvca.org/wp-content/uploads/2020/01/Q4_2019_PitchBook_NVCA_Venture_Monitor.pdf(accessed 15.11.2020).

13. Ofitsialnyi sait NASDAQ [Official website of NASDAQ]. Available at: https://www.nasdaq.com/market-activity/stocks (accessed 15.11.2020). 